\title{
A New Hybrid in the Nonlinear Part of Adomian Decomposition Method for Initial Value Problem of Ordinary Differential Equation
}

\author{
Adeyeye F. J. ${ }^{1}$, Igobi D. K. ${ }^{2}$ \& Ibijola E. A ${ }^{3}$ \\ ${ }^{1}$ Department of Maths/ComputerFederal University of Petroleum Resources, Effurrun, Nigeria. \\ ${ }^{2}$ Department of Mathematics/Statistics Federal University Wukari, Nigeria \\ ${ }^{3}$ Department of Mathematics, Ekiti State University,Ado-Ekiti, Nigeria \\ Correspondence: Igobi D. K., Department of Mathematics/Statistics, Federal University Wukari, Nigeria. E-mail: \\ dodiigobi@yahoo.com
}

Received: May 30, 2014 Accepted: June 21, 2014 Online Published: February 27, 2015

doi:10.5539/jmr.v7n1p102 URL: http://dx.doi.org/10.5539/jmr.v7n1p102

\begin{abstract}
In this paper, a new technique of Hybrid of Adomian polynomial is developed by the substitution of a One-step method of Taylor's series approximation of orders I and II into the nonlinear part of Adomian decomposition method .This yield a new Taylor series of Adomian Decomposition Method in the nonlinear part. The applications of the modified new hybrid polynomial to some classical problems give results that approximate the analytical solutions of the problems with minimal errors.
\end{abstract}

Keyword: Adomian decomposition method, Taylor series approximation, new hybrid of Adomian polynomial, ordinary differential equation

\section{Introduction}

Recently a great deal of interest has been focused on the application of Adomian's decomposition method to solve a wide variety of linear and nonlinear problems (Adomian, 1993). This method generates solutions in the form of a series whose terms are determined by a recursive relationship using the Adomian polynomials. Researchers who have used the Adomian's decomposition method have frequently enumerated on the advantages that it offers. Since it was first presented in the eighties, Adomian decomposition method has led to several modifications in an attempt to improve the accuracy or expand the application of the original method. One of such recent modification was presented in (Adomian \& Rach, 1996), and an improved version of it that converges slightly faster was presented in (Rach, 2008). But inspite of the various types of modified Adomian polynomial available, the algorithm of the original Adomian polynomial is more simple and convenient in application. Recently, a simple Mathematical program to compute the $\mathrm{n}^{\text {th }}$ term of the Adomian polynomial was developed in (Abbaoui \& Cherrault, 1994) and (Wazwaz, 1999), were Pade approximants were employed to obtain modified decomposition to generate an improved solution with minimal error. Several other research work on Adomian decomposition methods abound in (Adomian, 1993; Adomian \& Rach, 1996; Almazmumy, Hendi \& Bakodah, 2012).

The modifications of Adomian decomposition method arise from difficulties encounter in solving certain classical problems of differential equations. This usually involves slight change in the Adomian polynomial, which is aimed at improving the convergence of the series solution. The convergent concept of the Adomian decomposition method is addressed in (Abbaoui \& Cherrault, 1994; Adomian \& Rach, 1996; Ahmed, 2008), and its application to the initial value problem of ordinary differential equation is discussed in (Anguelov \& Lubuma, 2001; Wazwaz, 1998).

Therefore, the aim of this work is to generate a new Hybrid of Adomian polynomial in the Adomian decomposition method and then apply it to some classical equations and compare the result with their respective analytical solutions as shown in the tables and 3D graph.

\section{General Adomian Decomposition Method}

Considering a general nonlinear differential equation presented in (Adomian \& Cherruault, 1996) as

$$
F y=f,
$$


where $F$ is a nonlinear differential operator, $f$ and $y$ are functions of $x$. Rewriting the equation in the operator form

$$
L y+R y+N y=f,
$$

$L, R$ are invertible and non-invertible linear operator of $F$ respectively, and $N$ is a nonlinear operator representing the nonlinear term in $F$. Appling the inverse operator $L^{-1}$, the equation (2.1) implies

$$
L^{-1} L y=L^{-1} f-L^{-1} R y-L^{-1} N y .
$$

By the definition of $F$ as a differential operator and $L$ is linear, then $L^{-1}$ is an integrator, and with any given initial condition, $L^{-1} L y$ yield an equation $y$ of the form

$$
y(x)=g(x)-L^{-1} R y-L^{-1} N y,
$$

where $g(x)$ is the function generated by integrating $f$, using defined initial conditions. Employing the Adomian decomposition method on (2.2), an infinite series

$$
y(x)=\sum_{n=0}^{\infty} y_{n}(x),
$$

is obtained, with the nonlinear term defined as

$$
N y=\sum_{n=0}^{\infty} A_{n} .
$$

$A_{n}$ is the Adomian polynomials, which is determined by

$$
A_{n}=\frac{1}{n !}\left[\frac{d^{n}}{d \lambda^{n}} N y(\lambda)\right]_{\lambda=0} .
$$

Equation (2.2) can be express in terms of (2.3a) and (2.4) as,

$$
\sum_{n=0}^{\infty} y_{n}(x)=y_{0}-L^{-1} \sum_{n=0}^{\infty} R y_{n}-L^{-1} \sum_{n=0}^{\infty} A_{n}
$$

with a recursive relationship

$$
\begin{aligned}
& y_{0}=g(x), \\
& y_{n+1}=L^{-1} R y_{n}+L^{-1} A_{n} .
\end{aligned}
$$

Using equation (2.5), with the corresponding relation of (2.6) the $y$ series solution is determine immediately.

\section{The Modified New Hybrid of Adomian polynomial}

Considering the recurrent relation of the non-linear part of equation (2.3) as

$$
y_{n+1}(x)=L^{-1}\left(A_{n}\right),
$$

and the substitution of the non-local approximation defined in(Anguelov \& Lubuma, 2000; Anguelov \& Lubuma, 2001; Anguelov, \& Lubuma, 2003) as

$$
y_{n}^{2} \approx y_{n} y_{n+1},
$$

into (3.0),

$$
\sum_{n=0}^{\infty} y_{n}(x)=y_{0}+L^{-1}\left(y_{n} y_{n+1}\right)
$$


is obtained, where $y_{n}^{2}=A_{n}$.

By Taylor series expansion,

$$
y_{n+1}=y_{0}+h f\left(x_{n}, y_{n}\right)+\frac{h^{2}}{2 !} f^{\prime}\left(x_{n}, y_{n}\right)+\ldots+\frac{h^{n+1}}{n !} f^{n}\left(x_{n}, y_{n}\right),
$$

and rewriting equation (3.1) in terms of (3.2), the new hybrid of Adomian polynomial is thus

$$
\sum_{n=0}^{\infty} y_{n}(x)=y_{0}+L^{-1}\left(y_{0}\left(y_{n}+\sum_{n=0}^{\infty} \frac{h^{n+1}}{(n+1) !} f^{n}\left(x_{n}, y_{n}\right)\right)\right) \text {. }
$$

\section{Numerical Implementation of Equation (3.3)}

In this section some initial value problems are considered to show the efficiency of the modified equation (3.3).

Problem 1. Consider the initial value problem of the form

$$
y^{\prime}=y^{2}, y(0)=1 \text {. }
$$

Equation (4.0) has analytical solution

$$
y(x)=\frac{1}{1-x} .
$$

Solving (4.0) using the modified hybrid equation (3.3), the following terms of the series is obtained,

$$
\begin{aligned}
y_{0}(x)= & 1 \\
y_{1}(x)= & (1+h) x \\
y_{2}(x)= & (1+h)^{2}\left(\frac{x^{3}}{3}+\frac{1}{4} h(1+h) x^{4}\right) \\
y_{3}(x)= & \frac{1}{144}(1+h)^{4}\left(\frac{16 x^{7}}{7}+3 h(1+h) x^{8}+h^{2}(1+h)^{2} x^{9}+\frac{8}{15} h(1+h)^{2} x^{10}+\frac{12}{11} h^{2}(1+h)^{3} x^{11}\right. \\
& \left.+\frac{3}{4} h^{3}(1+h)^{4} x^{12}+\frac{9}{52} h^{4}(1+h)^{5} x^{13}\right) \\
y_{4}(x)= & \frac{1}{2985984}(1+h)^{8}\left(\frac{12288}{245} x^{15}+\frac{864}{7} h(1+h) x^{16}+\frac{13680}{119} h^{2}(1+h)^{2} x^{17}+\ldots\right) .
\end{aligned}
$$

And

$$
\sum_{n=0}^{4} y_{n}(x)=y_{0}+y_{1}+y_{2}+y_{3}+y_{4}+O(h) .
$$

Using the $\mathrm{y}_{\mathrm{n}}$ terms of (4.2) to obtained

$$
\begin{aligned}
\sum_{n=0}^{4} y_{n}(x) & =1+(1+h) x+(1+h)^{2}\left(\frac{x^{3}}{3}+\frac{1}{4} h(1+h) x^{4}\right) \\
+ & \frac{1}{144}(1+h)^{4}\left(\frac{16 x^{7}}{7}+3 h(1+h) x^{8}+h^{2}(1+h)^{2} x^{9}+\frac{8}{15} h(1+h)^{2} x^{10}+\frac{12}{11} h^{2}(1+h)^{3} x^{11}\right. \\
+ & \left.\frac{3}{4} h^{3}(1+h)^{4} x^{12}+\frac{9}{52} h^{4}(1+h)^{5} x^{13}\right) \\
+ & \frac{1}{2985984}(1+h)^{8}\left(\frac{12288}{245} x^{15}+\frac{864}{7} h(1+h) x^{16}+\frac{13680}{119} h^{2}(1+h)^{2} x^{17}+\ldots+O(h)\right)
\end{aligned}
$$


Table 4.1. Comparism of results of the New Hybrid ADM with the analytical solution at $\mathrm{h}=0.1$

\begin{tabular}{cccc}
\hline $\mathrm{X}$ & New Hybrid ADM & Analytical solution & Error \\
\hline 0.000 & 1.0000000000 & 1.0000000000 & 0.0000000000 \\
0.100 & 1.1111111641 & 1.1111111641 & 0.0000000000 \\
0.200 & 1.2500000000 & 1.2500000000 & 0.0000000000 \\
0.300 & 1.4285714626 & 1.4285714626 & 0.0000000000 \\
0.400 & 1.6666666269 & 1.6666666269 & 0.0000000000 \\
0.500 & 2.0000000000 & 2.0000000000 & 0.0000000000 \\
0.600 & 2.5000002384 & 2.5000002384 & 0.0000000000 \\
0.700 & 3.3333337307 & 3.3333339691 & -0.0000002384 \\
0.800 & 5.0000014305 & 5.0000019073 & -0.0000004768 \\
0.900 & 10.0000085831 & 10.0000095367 & -0.0000009537 \\
1.000 & & & \\
1.100 & -9.9999837875 & -9.9999856949 & 0.0000019073 \\
1.200 & -4.9999947548 & -4.9999957085 & 0.0000009537 \\
1.300 & -3.3333306313 & -3.3333311081 & 0.0000004768 \\
1.400 & -2.4999978542 & -2.4999985695 & 0.0000007153 \\
1.500 & -1.9999982119 & -1.9999990463 & 0.0000008345 \\
1.600 & -1.6666651964 & -1.6666659117 & 0.0000007153 \\
1.700 & -1.4285697937 & -1.4285708666 & 0.0000010729 \\
1.800 & -1.2499984503 & -1.2499995232 & 0.0000010729 \\
1.900 & -1.1111093760 & -1.1111106873 & 0.0000013113 \\
2.000 & -0.9999984503 & -0.9999997616 & 0.0000013113 \\
\hline
\end{tabular}

Table 4.1 shows the performance of the New-Hybrid ADM with the Analytical solution solution. At h=0.1 shows a better comparative iteration but with no value at $\mathrm{x}=1.0$. call point of singularity

Diagram1

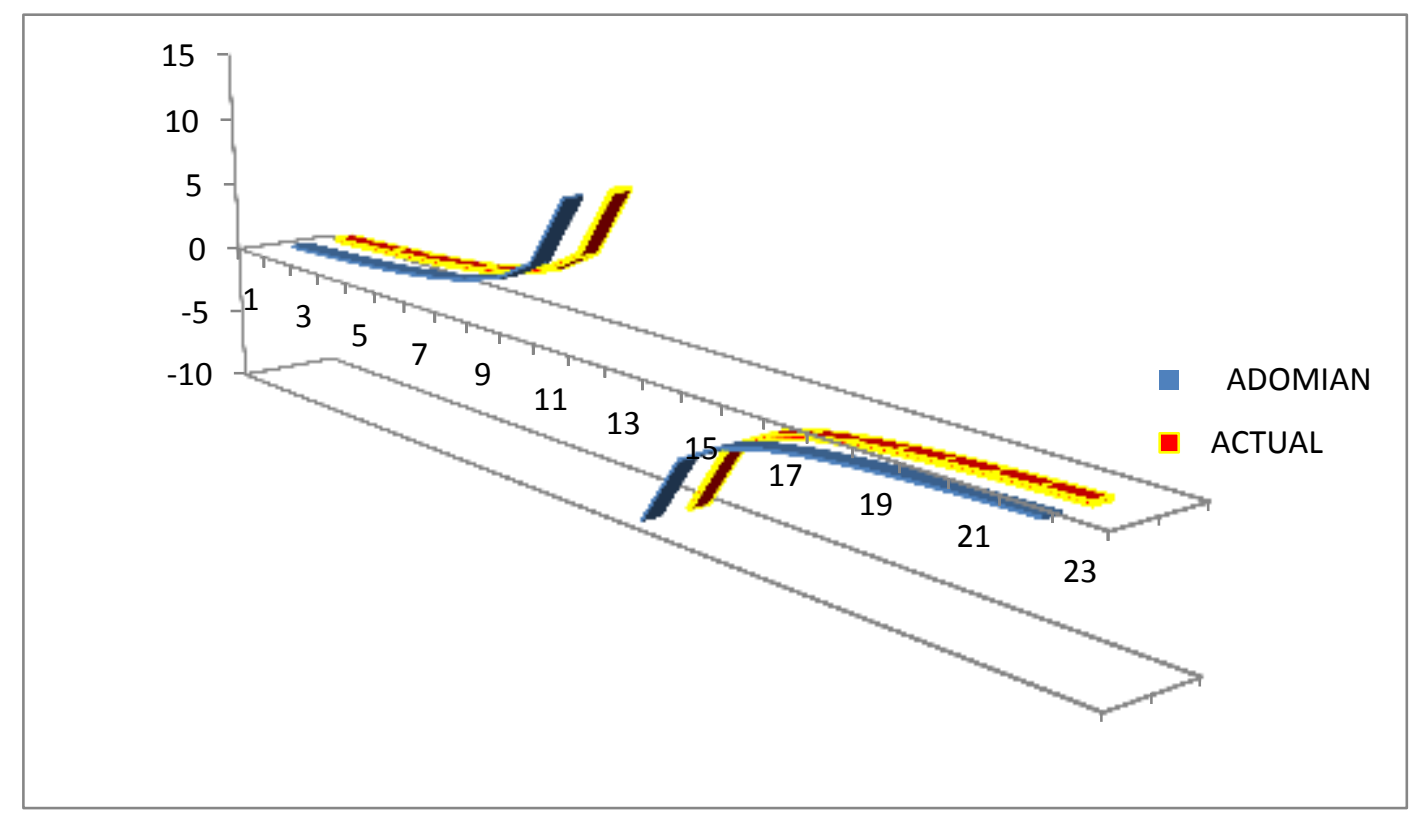

This shows reflection of the table above with the point of singularity $x=1.0$ clearly shown

PROBLEM 2 Consider the initial value problem of the form

$$
y^{\prime}=2 x y^{2}, y(0)=1 \text {. }
$$

Equation (4.5) has analytical solution 


$$
y(x)=\frac{1}{\left(1-x^{2}\right)} .
$$

Solving (4.5) using the modified hybrid equation (3.3), the following terms of the series is obtained,

$$
\begin{aligned}
y_{0}(x)= & 1 \\
y_{1}(x)= & x^{2}+\frac{4 h x^{3}}{3} \\
y_{2}(x)= & \frac{2}{27}\left(9 \frac{x^{6}}{2}+\frac{72 h x^{7}}{7}+6 h^{2} x^{8}+6 h x^{9}+\frac{108 h^{2} x^{10}}{5}+\frac{228 h^{3} x^{11}}{11}+\frac{32 h^{4} x^{12}}{3}\right) \\
y_{3}(x)= & \frac{1}{19683}\left(8 \left(\frac{2187 x^{14}}{56}+\frac{5832 h x^{15}}{35}+\frac{105705 h^{2} x^{16}}{392}+\frac{1458 x^{14}}{119} h\left(7+16 h^{2}\right) x^{17}\right.\right. \\
& +\frac{54}{35} h^{2}\left(309+35 h^{2}\right) x^{18}+\frac{7816824}{7315} h^{3} x^{19}+81 h^{2} \frac{\left(1155+28676 h^{2}\right) x^{20}}{1925} \\
& +\frac{27 h\left(3465+66528 h^{2}+136960 h^{4}\right) x^{21}}{5390}+\ldots
\end{aligned}
$$

And

$$
\sum_{n=0}^{3} y_{n}(x)=y_{0}+y_{1}+y_{2}+y_{3}+O(h) .
$$

Using the $y_{n}$ terms of (4.7) to obtained

$$
\begin{aligned}
\sum_{n=0}^{3} y_{n}(x) & =1+x^{2}+\frac{4 h x^{3}}{3} \\
& +\frac{2}{27}\left(9 \frac{x^{6}}{2}+\frac{72 h x^{7}}{7}+6 h^{2} x^{8}+6 h x^{9}+\frac{108 h^{2} x^{10}}{5}+\frac{228 h^{3} x^{11}}{11}+\frac{32 h^{4} x^{12}}{3}\right) \\
& +\frac{1}{19683}\left(8 \left(\frac{2187 x^{14}}{56}+\frac{5832 h x^{15}}{35}+\frac{105705 h^{2} x^{16}}{392}+\frac{1458 x^{14}}{119} h\left(7+16 h^{2}\right) x^{17}\right.\right. \\
& +\frac{54}{35} h^{2}\left(309+35 h^{2}\right) x^{18}+\frac{7816824}{7315} h^{3} x^{19}+81 h^{2} \frac{\left(1155+28676 h^{2}\right) x^{20}}{1925} \\
& \left.+\frac{27 h\left(3465+66528 h^{2}+136960 h^{4}\right) x^{21}}{5390}+\ldots\right)+O(h)
\end{aligned}
$$


Table 4.2. Comparism of results of the New Hybrid ADM with the analytical solution at $\mathrm{h}=0.1$

\begin{tabular}{|c|c|c|c|}
\hline $\mathrm{x}$ & New Hybrid ADM & Analytical solution & Error \\
\hline 0.000 & 1.0000000000 & 1.0000000000 & 0.0000000000 \\
\hline 0.100 & 1.0101009607 & 1.0101009607 & 0.0000000000 \\
\hline 0.200 & 1.0416666269 & 1.0416666269 & 0.0000000000 \\
\hline 0.300 & 1.0989011526 & 1.0989011526 & 0.0000000000 \\
\hline 0.400 & 1.1904761791 & 1.1904761791 & 0.0000000000 \\
\hline 0.500 & 1.3333332539 & 1.3333333731 & -0.0000001192 \\
\hline 0.600 & 1.5624998808 & 1.5625001192 & -0.0000002384 \\
\hline 0.700 & 1.9607838392 & 1.9607845545 & -0.0000007153 \\
\hline 0.800 & 2.7777767181 & 2.7777786255 & -0.0000019073 \\
\hline 0.900 & 5.2631564140 & 5.2631626129 & -0.0000061989 \\
\hline 1.000 & 4194295.2500000000 & -4194303.7500000000 & 8.5000000000 \\
\hline 1.100 & -4.7618808746 & -4.7618975639 & 0.0000166893 \\
\hline 1.200 & -2.2727103233 & -2.2727251053 & 0.0000147820 \\
\hline 1.300 & -1.4492542744 & -1.4492743015 & 0.0000200272 \\
\hline 1.400 & -1.0416306257 & -1.0416660309 & 0.0000354052 \\
\hline 1.500 & -0.7999210358 & -0.7999995351 & 0.0000784993 \\
\hline 1.600 & -0.6408274174 & -0.6410253048 & 0.0001978874 \\
\hline 1.700 & -0.5285925269 & -0.5291002393 & 0.0005077124 \\
\hline 1.800 & -0.4450853467 & -0.4464283586 & 0.0013430119 \\
\hline 1.900 & -0.3797498345 & -0.3831415772 & 0.0033917427 \\
\hline 2.000 & -0.3248179853 & -0.3333332241 & 0.0085152388 \\
\hline
\end{tabular}

Table 4.2 shows the performance of the New-Hybrid ADM with the Analytical solution and value at a neighborhood of $\mathrm{x}=1$

Diagram 2

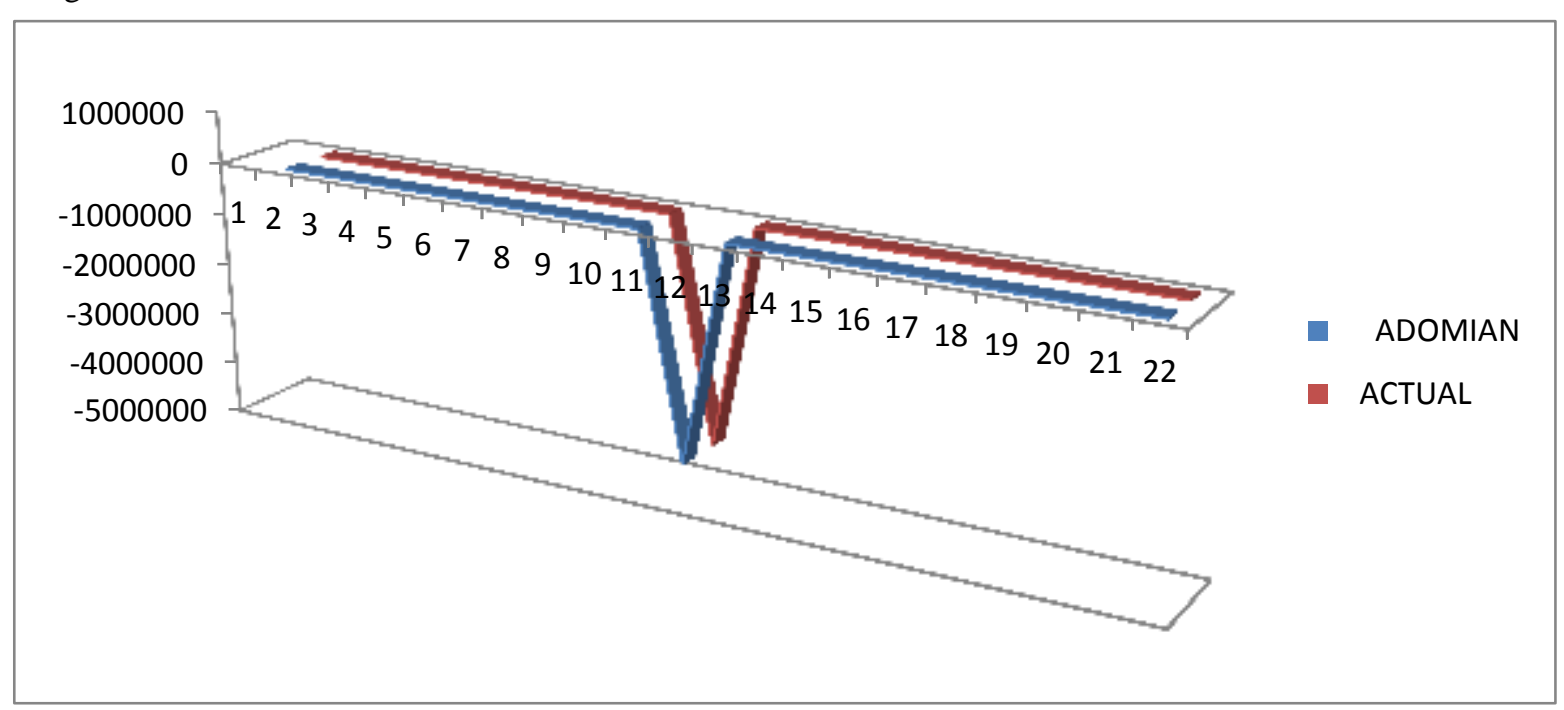

The figure shows a reflection of the table above

\section{Problem 3}

Consider the Abelian physical problem of [11] 


$$
y^{\prime}=1-y+y^{3}, \quad y(0)=0
$$

Solving (4.10) using the modified hybrid equation (3.3), the results is presented in table 3 as,

Table 3. Comparism of results of the Abelian physical problem at $\mathrm{h}=0.1$ with the results in (Omor, 2008)

\begin{tabular}{|c|c|c|c|}
\hline $\mathrm{x}$ & New Hybrid ADM & Omor (2008) $\quad$ Result & Error \\
\hline 0.000 & 0.0000000000 & 0.0000000000 & 0.0000000000 \\
\hline 0.100 & 0.0951841399 & 0.0951841399 & 0.0000000000 \\
\hline 0.200 & 0.1815637350 & 0.1815637350 & 0.0000000000 \\
\hline 0.300 & 0.2604402900 & 0.2604402900 & 0.0000000000 \\
\hline 0.400 & 0.3329962790 & 0.3329962790 & 0.0000000000 \\
\hline 0.500 & 0.4001302421 & 0.4001302123 & 0.0000000298 \\
\hline 0.600 & 0.4623936713 & 0.4623936117 & 0.0000000596 \\
\hline 0.700 & 0.5200300217 & 0.5200299621 & 0.0000000596 \\
\hline 0.800 & 0.5731159449 & 0.5731157660 & 0.0000001788 \\
\hline 0.900 & 0.6218037605 & 0.6218035221 & 0.0000002384 \\
\hline 1.000 & 0.6666671038 & 0.6666667461 & 0.0000003576 \\
\hline 1.100 & 0.7091473937 & 0.7091468573 & 0.0000005364 \\
\hline 1.200 & 0.7521032691 & 0.7521024942 & 0.0000007749 \\
\hline 1.300 & 0.8004610538 & 0.8004600406 & 0.0000010133 \\
\hline 1.400 & 0.8619684577 & 0.8619671464 & 0.0000013113 \\
\hline 1.500 & 0.9480487108 & 0.9480471611 & 0.0000015497 \\
\hline 1.600 & 1.0747585297 & 1.0747567415 & 0.0000017881 \\
\hline 1.700 & 1.2638460398 & 1.2638443708 & 0.0000016689 \\
\hline 1.800 & 1.5439125299 & 1.5439115763 & 0.0000009537 \\
\hline 1.900 & 1.9516746998 & 1.9516758919 & -0.0000011921 \\
\hline 2.000 & 2.5333287716 & 2.5333352089 & -0.0000064373 \\
\hline
\end{tabular}

Table 4.3 shows the performance of the New-Hybrid ADM with the Omor (2008) at $\mathrm{h}=.01$

Diagram3



The figure shows a reflection of the table above

\section{Conclusion}

The Taylor's series approximation of orders I and II is a good mathematical tool in the concept of the modified New Hybrid Adomian polynomial from the Adomian Decomposition Method. The application of the new Hybrid Adomian polynomial in solving some initial values problems (1-3), yield results that approximate the analytical solutions at step change of $\mathrm{h}=0.1$ with minimal errors. This is seen in results comparisms of tables 1-3 and diagrams 1-3 which confirmed the suitability of the New Hybrid for numerical approximation. 


\section{References}

Adomian, G. (1993). Solving Frontier problem of Physics. The Decomposition Method. Springer ,New York.

Abbaoui, K. J., \& Cherrault, Y. (1994). Convergence of Adomian's Method Applied to Differential Equations. International Journal of Computer/Mathematics Application, 28(5), 103-109.

Adomian, G., \& Rach, C. (1996). Modified Adomian Polynomial. Mathematical and Computer Modeling Journal, 24(11), 39-46. http://dx.doi.org/10.1016/S0895-7177(96)00171-9

Adomian, G., \& Cherruault, Y. (1996). Abbaoui K. A Nonpertubative Analytical Solution of Immune Response with Time-delays and possible Generalization. Math. Comput. Modelling, 24(11), 89-96. http://dx.doi.org/10.1016/S0895-7177(96)00167-7

Ahmed, A. H. M. (2008). Convergence Analysis and Numerical Approximation (M.Sc Thesis).

Almazmumy, M., Hendi, F. A., \& Bakodah, H. A. (2012). Recent modification of Adomian Decomposition Method for Initial Value problem in Ordinary Differential Equations. American journal of Computational Mathematics, 2, 228-234. http://dx.doi.org/10.4236/ajcm.2012.23030

Anguelov, R., \& Lubuma, J. M. S. (2000). Nonstandard Finite Difference Method by Nonlocal Approximation. Keynote address at the South Africa Mathematical Society, Pretoria, South Africa 16-18 October. Notices of S.A. Math. Soc., 31, 143-543.

Anguelov, R., \& Lubuma, J. M. S. (2001). Contributions of the Mathematics of the Nonstandard Finite Method and Applications. Num, Math. Partial Differential Equations, 17(5), 518-543. http://dx.doi.org/10.1002/num.1025

Anguelov, R., \& Lubuma, J. M. S. (2003). Nonstandard Finite Difference Method by Nonlocal Approximation. Mathematics and Computers in Simulation Journal, 6, 465-475.

http://dx.doi.org/10.1016/S0378-4754(02)00106-4

Omor, K. T. (2008). Adomian Deposition method for solving Abelian Differential equations. Journal of Applied Science, 8(10), 1962-1966. http://dx.doi.org/10.3923/jas.2008.1962.1966

Rach, C. (2008). A New Definition of the Adomian Polynomial. Kybermeters, 37(7), 910-55.

Wazwaz, A. (1999). Analytical Approximations and Pade approximations for Volterras Population Model. Appl. Math. Computer, 100, 13-25. http://dx.doi.org/10.1016/S0096-3003(98)00018-6

Wazwaz, A. (1998). A Comparison between Adomian decomposition method and Taylor Series Method in the Series Solutions. Appl. Math. Computer, 97, 37-44. http://dx.doi.org/10.1016/S0096-3003(97)10127-8

\section{Copyrights}

Copyright for this article is retained by the author(s), with first publication rights granted to the journal.

This is an open-access article distributed under the terms and conditions of the Creative Commons Attribution license (http://creativecommons.org/licenses/by/3.0/). 